\title{
Bilateral pneumonectomy to treat uncontrolled sepsis in a patient awaiting lung transplantation
}

\author{
Marcelo Cypel, MD, ${ }^{\mathrm{a}, \mathrm{b}}$ Thomas Waddell, MD, ${ }^{\mathrm{a}, \mathrm{b}}$ Lianne G. Singer, MD, ${ }^{\mathrm{a}, \mathrm{c}}$ Lorenzo del Sorbo, MD, ${ }^{\mathrm{d}}$ \\ Eddy Fan, MD, ${ }^{\mathrm{d}}$ Matthew Binnie, MD,${ }^{\mathrm{a}, \mathrm{c}}$ Niall D. Ferguson, MD, ${ }^{\mathrm{d}}$ and Shaf Keshavjee, MD, ${ }^{\mathrm{a}, \mathrm{b}}$ Toronto, \\ Ontario, Canada
}

\footnotetext{
From the ${ }^{a}$ Toronto Lung Transplant Program, ${ }^{\mathrm{b}}$ Division of Thoracic Surgery, Department of Surgery, and Divisions of ${ }^{\mathrm{c}}$ Respirology and ${ }^{\mathrm{d}}$ Critical Care Medicine, University Health Network, University of Toronto, Toronto, Ontario, Canada.

Disclosures: Authors have nothing to disclose with regard to commercial support.

Received for publication Sept 13, 2016; revisions received Nov 2, 2016; accepted for publication Nov 16, 2016; available ahead of print Dec 22, 2016.

Address for reprints: Shaf Keshavjee, MD, University of Toronto, Toronto General Hospital, 200 Elizabeth St, 9N946, Toronto, Ontario, Canada M5G 2C4 (E-mail: shaf.keshavjee@uhn.ca).

J Thorac Cardiovasc Surg 2017;153:e67-9

$0022-5223 / \$ 36.00$

Copyright (c) 2016 by The American Association for Thoracic Surgery

http://dx.doi.org/10.1016/j.jtcvs.2016.11.031
}

\begin{abstract}
A 32-year-old woman with advanced cystic fibrosis lung disease was relatively stable on the waiting list for lung transplantation, but contracted $\mathrm{H} 1 \mathrm{~N} 1$ influenza. She required intubation and mechanical ventilation, but her condition progressively worsened, ultimately necessitating bridging with veno-venous (VV) extracorporeal life support (ECLS). Unfortunately, no donor lungs were available for 10 days. During this time, septic shock developed from Gram-negative bacteremia (Pseudomonas aeruginosa) due to worsening lung infection (Figure 1, A).

Despite therapy with broad-spectrum antibiotics and appropriate fluid resuscitation, acute kidney injury developed, requiring high doses of inotropes and vasopressors (norepinephrine $0.5 \mu \mathrm{g} / \mathrm{kg} /$ minute, vasopressin $6 \mathrm{U} /$ hour, and epinephrine boluses). Maintaining oxygenation was difficult despite $7 \mathrm{~L}$ of VV ECLS flow (partial pressure of oxygen in arterial blood, $52 \mathrm{mmHg}$, partial pressure of carbon dioxide, $50 \mathrm{mmHg}$; $\mathrm{pH} 7.19$; oxygen saturation, $82 \%$ ).

The patient's condition continued to worsen, and her prognosis was grim, with survival believed to be measured in hours at this stage. After detailed discussion with the patient's family, and knowing her previously expressed wishes for the most aggressive therapy, we sought source control of her sepsis by performing bilateral pneumonectomy and mechanically bridged her to lung transplantation. To our knowledge, this had never been achieved before.
\end{abstract}

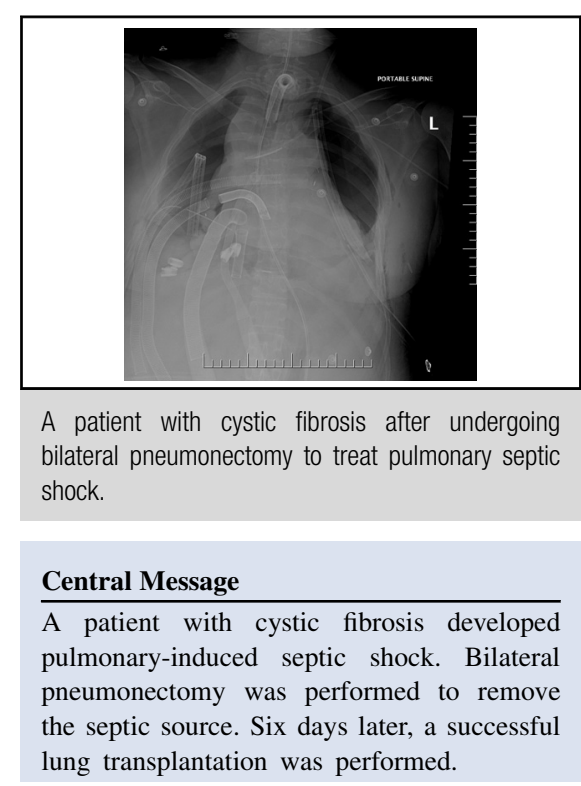

See Editorial Commentary page e71.
The operation began with a clamshell incision in the fourth intercostal space. The pericardium was opened and she was placed on central veno-arterial (VA; right atrium to aorta) ECLS at $5 \mathrm{~L} /$ minute. The VV ECLS was weaned, and the cannulas were removed. Bilateral pneumonectomy was performed. The main bronchi, pulmonary arteries, and veins were stapled closed, and the pleural spaces were irrigated with saline. The vascular stumps were left extra long for subsequent transplantation. Via the right hilum, a pumpless Novalung device (Xenios, Heilbronn, Germany) was then placed from the right pulmonary artery (28 Fr single-stage venous cannula) to the left atrium via the right superior pulmonary vein (24 Fr right-angled cannula) to provide the "lung" for the remaining flow in the right ventricle to empty into and transfer oxygenated blood to the left atrium. The patient was transferred back to the intensive care unit in this state, with no lungs 


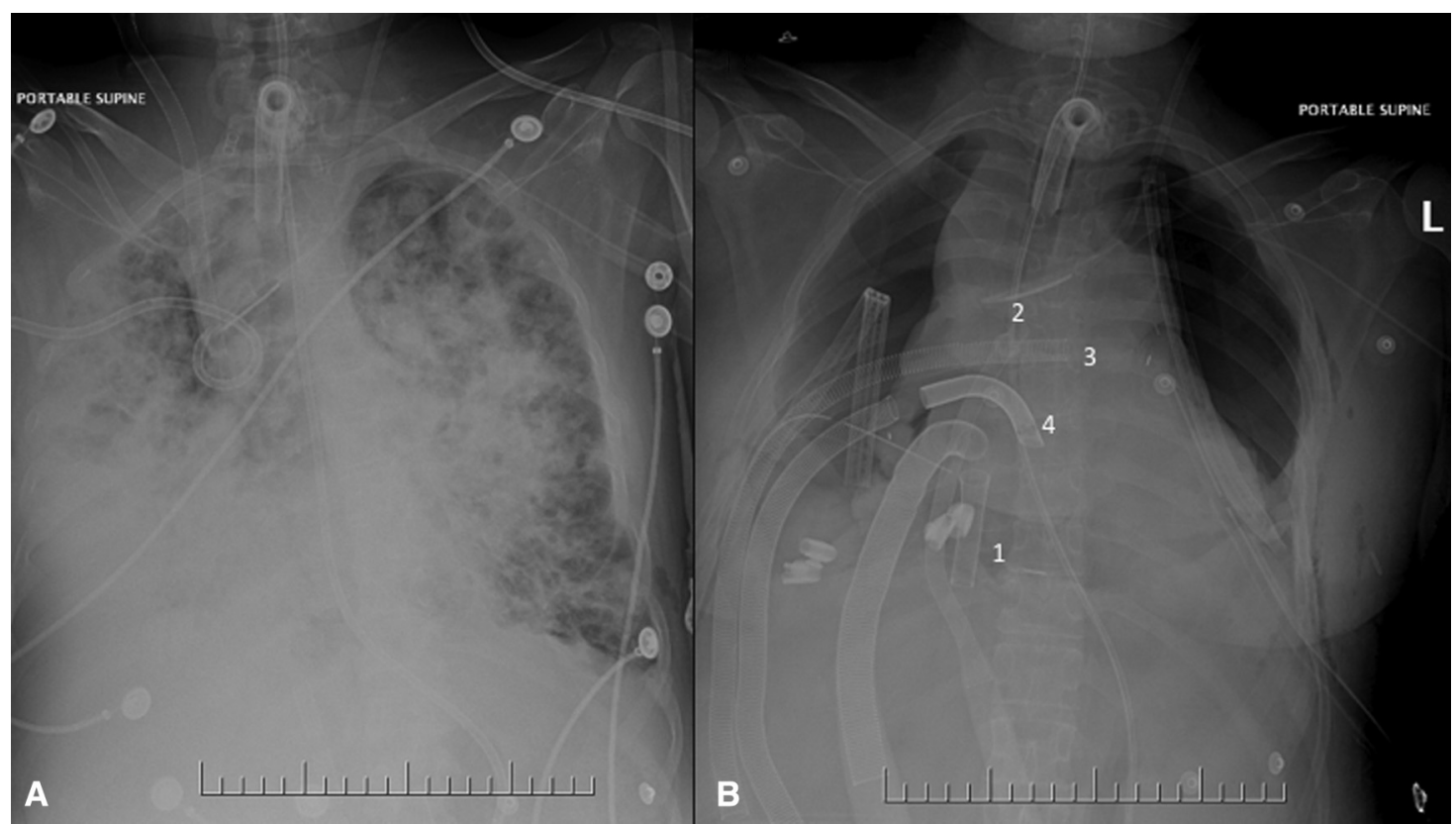

FIGURE 1. A, Severe pneumonia in the background of end-stage cystic fibrosis. B, Patient in the intensive care unit with no lungs for 6 days. 1 , Right atrial venous drainage cannula; 2, aortic return cannula; 3, pulmonary arterial cannula; 4, pulmonary vein arterial cannula (left atrial).

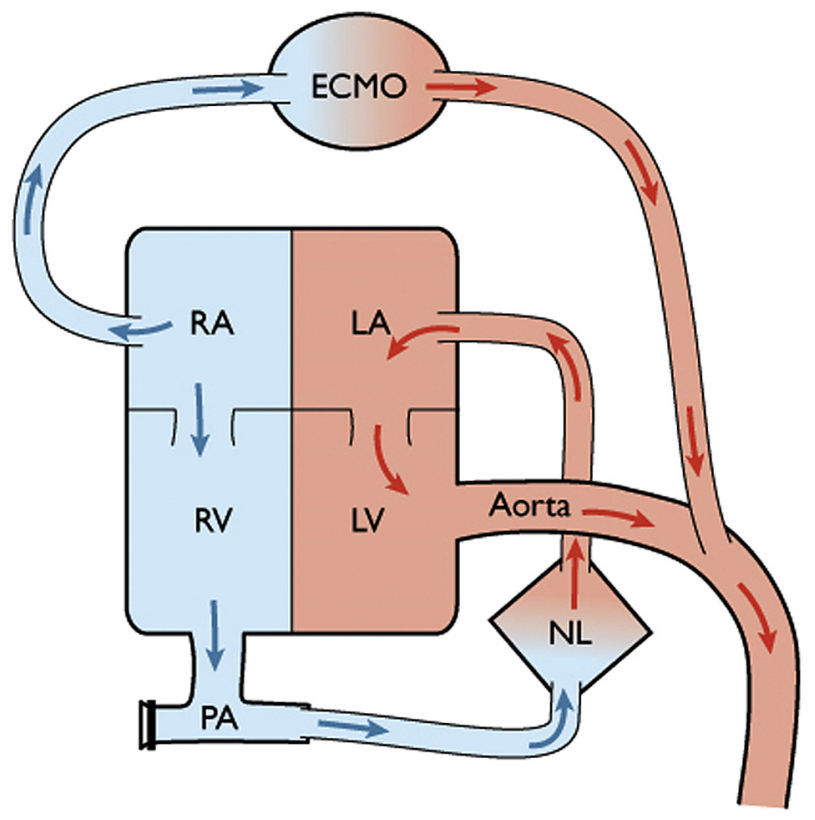

FIGURE 2. Diagram of mechanical support before transplantation in the absence of lungs. Flow is directed from the right ventricle to the aorta in a standard veno-arterial extracorporeal membrane oxygenation configuration. Residual flow passing from the right atrium to the pulmonary artery is then shunted and oxygenated via the Novalung to the left atrium, allowing the right ventricle to provide pulsatility against a low-resistance system. ECMO, Extracorporeal membrane oxygenation; $R A$, right atrium; $L A$, left atrium; $R V$, right ventricle; $L V$, left ventricle; $P A$, pulmonary artery; $N L$, Novalung.
(Figure 1, B). A diagram of the mechanical support applied to the patient is shown in Figure 2.

Following this procedure, the patient showed almost immediate and dramatic improvement, and we were able to discontinue all vasoactive support before leaving the operating room. Extracorporeal membrane oxygenation flow was maintained at 2.5 to $3 \mathrm{~L} /$ minute, and Novalung flows ranged from 1.5 to $2.5 \mathrm{~L} /$ minute. ACT was maintained between 160 and 180 seconds.

The patient's condition improved progressively over the next few days. Six days later, we obtained suitable donor lungs and successfully performed the final step in this staged bilateral lung transplantation procedure. The transplantation procedure was uncomplicated. Left lung implantation was followed by decannulation of the Novalung, then right lung implantation. At the end of the procedure, the central VA ECLS was weaned, and patient demonstrated excellent hemodynamics and International Society for Heart and Lung Transplantation primary graft dysfunction grade 1 . Her chest imaging on ICU arrival is shown in Figure 3. At 4 months after surgery, although still needing twice-weekly ambulatory dialysis, she was doing very well clinically, fully mobile and breathing normally on room air. 


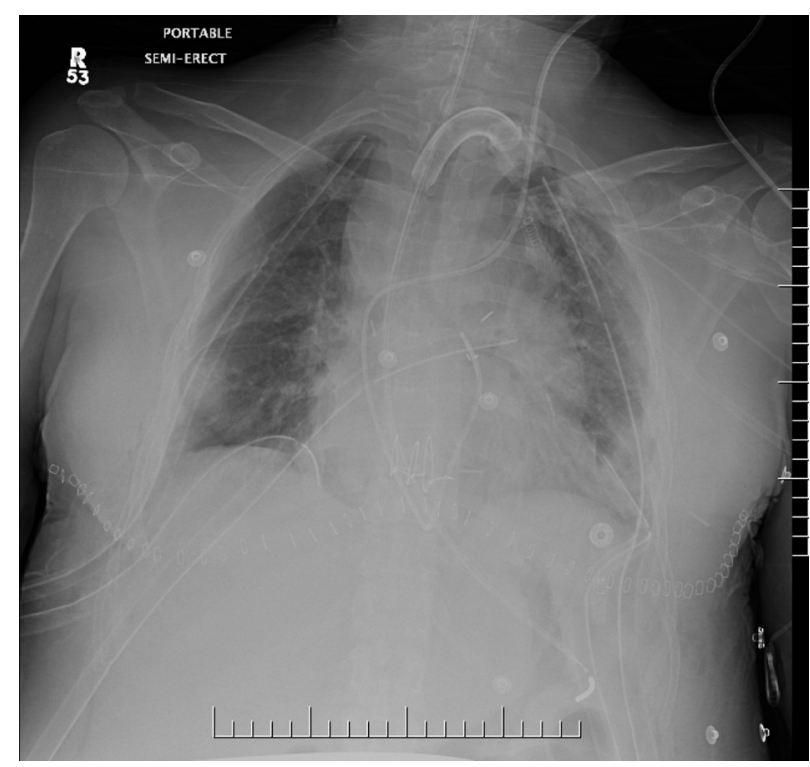

FIGURE 3. Immediate post-bilateral lung transplantation.

\section{DISCUSSION}

Patients with cystic fibrosis are common candidates for ECLS as a bridge to lung transplantation; however, centers bridging these patients have often experienced situations in which pulmonary failure and sepsis eventually develop, precluding subsequent transplantation. With improvements in ECLS technology and an improved understanding of the different ECLS modes available, we hypothesized that the approach of bilateral lung explantation in a situation of septic shock driven by pulmonary infection in selected patients awaiting lung transplantation could potentially provide a life-saving option. Essentially this follows standard infectious disease and surgical principles of source control of a septic focus. We also felt that the chosen ECLS configuration was theoretically ideal. VA central ECLS provides the flexibility of flow adjustment based on the patient's hemodynamics (which can be variable in the context of sepsis), whereas the pumpless Novalung serves as a temporary artificial lung for the right ventricle to empty while filling the left atrium with oxygenated blood. In the subject patient, a 1:1 flow ratio of VA ECLS flow to Novalung flow $(2.5 \mathrm{~L} /$ minute in each of the devices) appeared to be ideal.

In summary, we believe that bilateral pneumonectomy can be considered in selected patients with pulmonarydriven septic shock who are awaiting lung transplantation. 